\title{
ORIGINAL ARTICLE \\ Home-loving boreal hare mitochondria survived several invasions in Iberia: the relative roles of recurrent hybridisation and allele surfing
}

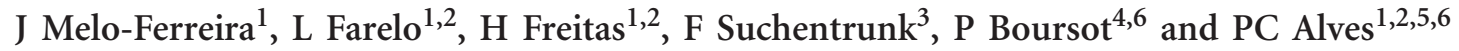

Genetic introgression from a resident species into an invading close relative can result from repeated hybridisation along the invasion front and/or allele surfing on the expansion wave. Cases where the phenomenon is massive and systematic, such as for hares (genus Lepus) in Iberia, would be best explained by recurrent hybridisation but this is difficult to prove because the donor populations are generally extinct. In the Pyrenean foothills, Lepus europaeus presumably replaced Lepus granatensis recently and the present species border is parallel to the direction of invasion, so that populations of $L$. granatensis in the contact zone represent proxies of existing variation before the invasion. Among three pairs of populations sampled across this border, we find less differentiation of mitochondrial DNA (mtDNA) across than along it, as predicted under recurrent hybridisation at the invasion front. Using autosomal microsatellite loci and $\mathrm{X}$ - and $\mathrm{Y}$-linked diagnostic loci, we show that admixture across the border is quasi-absent, making it unlikely that lack of interspecific mtDNA differentiation results from ongoing gene flow. Furthermore, we find that the local species ranges are climatically contrasted, making it also unlikely that ongoing ecologydriven movement of the contact account for mtDNA introgression. The lack of mtDNA differentiation across the boundary is mostly due to sharing of mtDNA from a boreal species currently extinct in Iberia (Lepus timidus) whose mitochondria have thus remained in place since the last deglaciation despite successive invasions by two other species. Home-loving mitochondria thus witness past species distribution rather than ongoing exchanges across stabilised contact zones.
\end{abstract}

Heredity (2014) 112, 265-273; doi:10.1038/hdy.2013.102; published online 23 October 2013

Keywords: mtDNA introgression; hybridisation; allele surfing; Lepus spp.; microsatellites; sex-linked loci

\section{INTRODUCTION}

The invasion of the territory of a resident species by an expanding one, with hybridisation during the process, may lead to introgression from the resident species into the invading one, and this is predicted to particularly affect regions of the genome with low rates of intraspecific migration (Currat et al., 2008). The amount of introgression is predicted to be enhanced by higher rates of hybridisation, but also by higher intensity of drift at the front of invasion (when the invading species is still relatively rare and more likely to hybridise) that can accidentally bring introgressed alleles to high frequencies. The more rapid the demographic growth in the invaded territories, the more likely are such high frequencies of introgressed alleles to be further propagated, by a phenomenon designated 'allele surfing' on an expansion wave (Currat et al., 2008; Excoffier and Ray, 2008). Such traces of introgression can gradually be erased by migration from the native species range not affected by introgression, but the amplitude and speed of this phenomenon is expected to depend on migration rate. In species with male-biased migration and female philopatry, as is thought to be the case for most mammals, femaletransmitted mitochondrial DNA (mtDNA) are thus expected to be particularly subject to persistent introgression. This simple demographic process may then explain why substantial mtDNA introgression has been repeatedly observed in mammals, and is often more extensive than for the nuclear genome (Petit and Excoffier, 2009). In theory, rare hybridisation events could suffice for the process to occasionally occur, if drift was important enough at the early stages of invasion and consecutive geographic and demographic expansions rapid enough. However, in some instances such as for the three species of hares (genus Lepus) present in Iberia, the phenomenon appears to have occurred repeatedly and independently, in a quasideterministic manner (Melo-Ferreira et al., 2005, 2007, 2011, 2012). Such a pattern would be best accounted for either if it was driven by selection or if hybridisation occurred repeatedly along the front of advance of the invading species in all cases. Estimating the rate of hybridisation along the front of invasion by observing genetic variation after the invasion has occurred may however be challenging because generally, at the time of observation, the donor populations of the invaded species are extinct. Indirect arguments based on the observation of increasing variability in the direction of invasion may not be conclusive because this pattern could result either from

${ }^{1} \mathrm{CIBIO}$, Centro de Investigação em Biodiversidade e Recursos Genéticos, Universidade do Porto, InBIO Laboratório Associado, Vairão, Portugal; ${ }^{2}$ Departamento de Biologia, Faculdade de Ciências da Universidade do Porto, Porto, Portugal; ${ }^{3}$ Research Institute of Wildlife Ecology, University of Veterinary Medicine, Vienna, Austria; ${ }^{4}$ Institut des Sciences de I'Evolution, Université Montpellier 2, CNRS IRD, Montpellier, France and ${ }^{5}$ Wildlife Biology Program, College of Forestry and Conservation, University of Montana, Missoula, MT, USA

${ }^{6}$ These authors contributed equally.

Correspondence: Dr J Melo-Ferreira, CIBIO, Centro de Investigação em Biodiversidade e Recursos Genéticos, Universidade do Porto, InBIO Laboratório Associado, Campus Agrário de Vairão, 4485661 Vairão, Portugal.

E-mail: jmeloferreira@cibio.up.pt

Received 24 April 2013; revised 23 August 2013; accepted 9 September 2013; published online 23 October 2013 
repeated introgression or from surfing of de novo mutations on the invasion wave.

The Iberian Peninsula has been an area of recurrent admixture at different timescales among species of hares (genus Lepus), because the three extant species have been heavily affected by mtDNA introgression from a fourth species, the mountain hare, Lepus timidus (Alves et al., 2003; Melo-Ferreira et al., 2005), which was present in Iberia at the end of the last glacial period (Altuna, 1970) but is currently distributed only in Northern Eurasia and in some isolated populations in Scotland, Ireland and the Alps. The broom hare Lepus castroviejoi, which is endemic to the Cantabrian Mountains, was the most massively affected because its aboriginal mtDNA lineage appears to have been totally replaced by mtDNA of L timidus origin during two waves of hybridisation, the more recent one during the last deglaciation period and the earlier one during the Pleistocene (MeloFerreira et al., 2012). This suggests that hybridisation with L. timidus has been relatively frequent but detailed inferences of its frequency during these two episodes would need more population genetics data than presently available on this species. The Iberian hare, Lepus granatensis, is endemic to Iberia, occupies most of the Peninsula and has been studied in more detail in this respect. Populations of the northern half of its range harbour high frequencies of $L$. timidus mtDNA, with increasing frequencies towards the North (MeloFerreira et al., 2005). This would fit the idea that L. granatensis replaced $L$. timidus in the Northern half of Iberia, favoured by climate warming after the last glacial maximum (Melo-Ferreira et al., 2007). There is evidence of a strong East-West partition of three introgressed mtDNA sublineages, which indicates that the phenomenon occurred at least three times independently during this process (Melo-Ferreira et al., 2011). Therefore, hybridisation was frequent enough for introgression to happen systematically in different parts of the invasion range (although it cannot be completely excluded that selection had a role; see Melo-Ferreira et al., 2011 for discussion). For one of these phylogeographic groups of introgressed timidus mtDNA there is also evidence of increased nucleotide diversity towards the north (in the direction of the presumed invasion; Melo-Ferreira et al., 2007). While this pattern would fit the idea of repeated introgression along the invasion front, it was not possible to formally exclude that it results from surfing of de novo mutations (Melo-Ferreira et al., 2011).

Here we take advantage of the peculiar situation of the brown hare, L. europaeus, to further tackle this question. In the Iberian Peninsula, this species is restricted to the Pyrenean foothills, but has a broad distribution north of the Pyrenees. This species likely invaded Iberia only when it colonised Western Europe (Stamatis et al., 2009) after the last glacial maximum, a period characterised by major range changes of numerous European taxa promoted by deglaciation (Hewitt, 2000). Iberian populations of this species harbour very high frequencies of mtDNA of $L$. timidus origin, which appears almost fixed (Melo-Ferreira et al., 2005; Alves et al., 2008). This is likely to result from the colonisation of Iberia by $L$. europaeus and its replacement of a resident species that harboured timidus mtDNA. Such a species could have been either L. timidus if it was still present when L. europaeus arrived (which is uncertain) or L. granatensis if it already had high frequencies of timidus mtDNA, which is plausible. L. castroviejoi is unlikely to have been the donor of timidus mtDNA to L. europaeus because although it is fixed for timidus-type mtDNA, its most frequent mtDNA lineage is clearly distinct from those found in L. europaeus (that resemble more those in L. granatensis; MeloFerreira et al., 2007, 2012). Furthermore, in a survey of diagnostic SNPs at 10 autosomal loci, Melo-Ferreira et al. (2009) found sporadic evidence of introgression from L. timidus into L. granatensis, but none into L. europaeus. However, there was some evidence of nuclear introgression from L. granatensis into L. europaeus (contradicting previous suggestions that these species did not hybridise; Estonba et al., 2006), which may indicate that L. europaeus replaced L. granatensis when entering Iberia and invading the Pyrenean foothills. What makes the situation interesting for the question we address here is thus that the present zone of contact between the two species is parallel to the likely East-West direction of invasion (the distribution of $L$. europaeus in Iberia being restricted to a narrow strip bordered to the north by either the Pyrenees or the ocean, this must have been the major direction of colonisation). The genetic makeup of the L. granatensis populations south of the present contact zone should therefore reflect to a certain extent that of the populations that existed a little further north before they were replaced by L. europaeus. If hybridisation occurred repeatedly at the front of invasion, populations sampled across the contact zone should resemble each other more than populations sampled along the zone on either side of it. Such a pattern would not be expected if introgression had occurred rarely and only at the beginning of the invasion process. If introgression was restricted to mtDNA, this expected pattern should be found for mtDNA but not for nuclear markers, which should in fact show the reverse pattern: greater differentiation across the contact zone than along it. We therefore sampled pairs of populations across the contact zone between $L$. europaeus and L. granatensis and measured genetic differentiation using mtDNA and nuclear markers. We found the contrasted pattern between the two types of markers that sustains the hypothesis of recurrent hybridisation during invasion. This study also characterises for the first time not only past but also present exchanges among these two species. Finally, we provide evidence for a climatic contrast between the species ranges in our study area, which suggests a role for ecology in their past and present interactions.

\section{MATERIALS AND METHODS}

\section{Sampling and microsatellite genotyping}

A total of 342 hare tissue samples (194 L. granatensis, 109 L. europaeus and 39 L. timidus) were collected from several localities in Europe (Figure 1, Table 1). Three pairs of populations were sampled on opposite sides of the contact zone between L. granatensis and L. europaeus in Northern Iberia (ALA1-ALA2, NAV1-NAV2 and ZAR-JAC; see Figure 1). The other populations sampled served as parental populations to improve resolution in the assessment of admixture in the contact zone. They were broadly distributed in Iberia for L. granatensis and from Central Europe for L. europaeus (Figure 1). Two sampling sites were surveyed for L. timidus, that in the Italian Alps represent the present southernmost distribution of the species.

Total genomic DNA was extracted from frozen liver or ear tissue using a standard high-salt protocol. A set of six microsatellite loci was chosen from previously published works. Loci Sat2, Sat8, Sat12 (Mougel et al., 1997) and INRACCDDv358 (Chantry-Darmon et al., 2005) were originally developed for the European rabbit (Oryctolagus cuniculus), also a member of Leporidae, while Lsa2 (Kryger et al., 2002) was specifically developed for hares and Sol30Le was adapted for hares from a rabbit-specific locus (Fickel et al., 1999). All loci have dinucleotide repeat motifs except Sat12, which has a tetranucleotide motif. The microsatellites were PCR-amplified using $0.25 \mathrm{ng}$ of genomic DNA per reaction, with an initial denaturation step of $3 \mathrm{~min}$ at $94{ }^{\circ} \mathrm{C}$, followed by 30 cycles of $30 \mathrm{~s}$ at $94^{\circ} \mathrm{C}, 30 \mathrm{~s}$ at $40-58^{\circ} \mathrm{C}$ (see Supplementary Table S1) and $30 \mathrm{~s}$ at $72^{\circ} \mathrm{C}$. A final 15 -min elongation step at $72^{\circ} \mathrm{C}$ was applied. Fluorescently labelled primers allowed detection of the PCR fragments on an ABI PRISM 3130 automated sequencer (Applied Biosystems, Foster City, CA, USA). To validate the allele calling, which was done with GeneMapper Software v3.7 (Applied Biosystems), control individuals were included in every run and a randomly chosen $\sim 15 \%$ portion of the data set was repeated. 


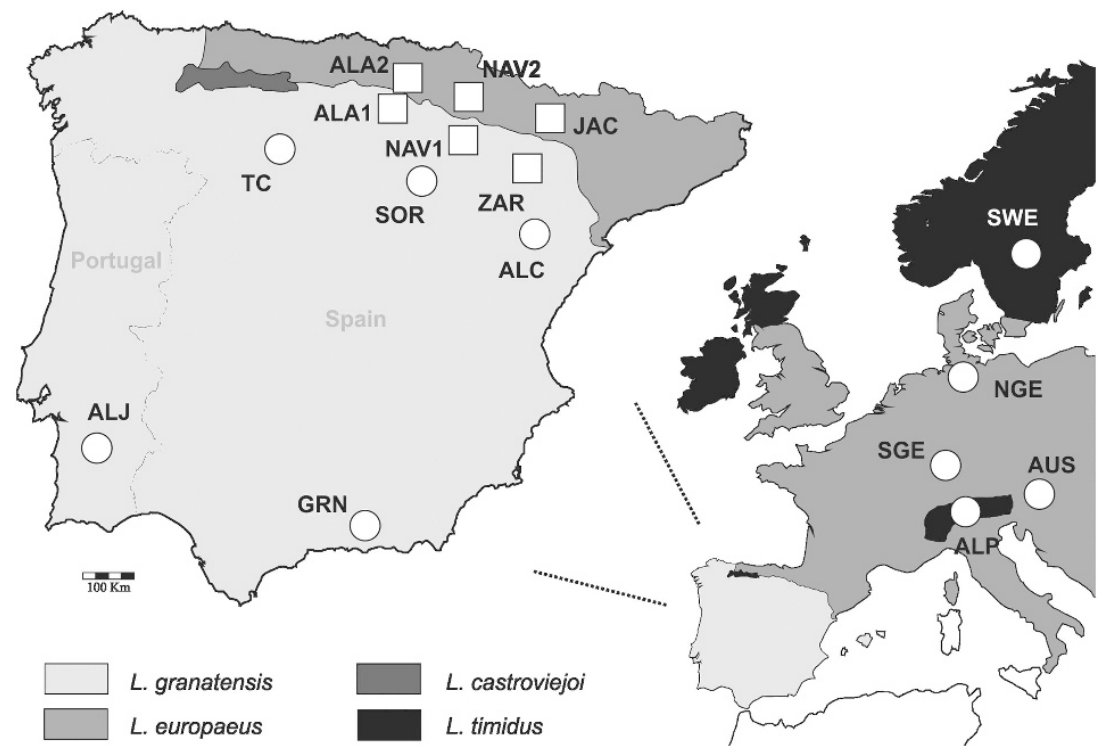

Figure 1 Geographic distribution of hares in Western Europe and in the Iberian Peninsula, and localities sampled in this study (see codes and sample sizes in Table 1). Squares indicate populations sampled close to the contact zone and circles putative parental populations of each species.

Table 1 Number of specimens analysed for the studied molecular markers and absolute frequencies of the mtDNA (cytochrome $b$ ) and Y-chromosome (Sry) lineages identified in the L. granatensis and L. europaeus specimens from Álava, Spain

\begin{tabular}{|c|c|c|c|c|c|c|c|c|c|c|c|c|c|c|}
\hline \multirow[t]{3}{*}{ Spp } & \multirow[t]{3}{*}{ Code } & \multirow[t]{3}{*}{ Locality } & \multirow[t]{3}{*}{ Micros. } & \multicolumn{4}{|c|}{$m t D N A$} & \multirow{2}{*}{\multicolumn{4}{|c|}{$\begin{array}{c}\text { X chromosome } \\
\text { Sequences }\end{array}$}} & \multirow{2}{*}{\multicolumn{3}{|c|}{$\begin{array}{c}\text { Y Chromosome } \\
\text { PCR-RFLPc }\end{array}$}} \\
\hline & & & & \multirow{2}{*}{$\begin{array}{c}\text { Sequences }^{a} \\
\text { tim }\end{array}$} & \multicolumn{3}{|c|}{$P C R-R F L P^{\mathrm{b}}$} & & & & & & & \\
\hline & & & & & gra & eur & tim & Phka2 ${ }^{\mathrm{d}}$ & Smcx & $M s n^{\mathrm{e}}$ & Hprt1 & gra & \multirow[t]{2}{*}{ eur } & tim \\
\hline \multirow[t]{8}{*}{ gra } & ALJ & Aljustrel, Portugal & 19 & & & & & & & & & & & \\
\hline & GRN & Granada, Spain & 20 & & & & & & & & & & & \\
\hline & ALC & Alcañiz, Spain & 16 & & & & & & & & & & & \\
\hline & SOR & Soria, Spain & 13 & & & & & & & & & & & \\
\hline & $\mathrm{TC}$ & Tierra de Campos, Spain & 11 & & & & & & & & & & & \\
\hline & ZAR & Zaragoza, Spain & 41 & 30 & & & & & & & & & & \\
\hline & NAV1 & Navarra, Spain & 28 & 22 & & & & & & & & & & \\
\hline & ALA1 & Álava, Spain & 46 & 13 & 34 & 0 & 14 & 28 & 33 & 36 & 17 & 25 & 0 & 0 \\
\hline \multirow[t]{6}{*}{ eur } & ALA2 & Álava, Spain & 51 & 22 & 17 & 2 & 34 & 32 & 29 & 31 & 25 & 0 & 9 & 0 \\
\hline & NAV2 & Navarra, Spain & 7 & 6 & & & & & & & & & & \\
\hline & $J A C$ & Jaca, Spain & 11 & 7 & & & & & & & & & & \\
\hline & SGE & Southern Germany & 8 & & & & & & & & & & & \\
\hline & NGE & Northern Germany & 14 & & & & & & & & & & & \\
\hline & AUS & Austria & 18 & & & & & & & & & & & \\
\hline \multirow[t]{3}{*}{ tim } & ALP & Italian Alps & 20 & & & & & 3 & 1 & 3 & 1 & & & \\
\hline & SWE & Sweden & 19 & & & & & 7 & 2 & 4 & 2 & & & \\
\hline & & Total & 342 & 100 & 51 & 2 & 48 & 70 & 65 & 74 & 45 & 25 & 9 & 0 \\
\hline
\end{tabular}

Abbreviations: micros., microsatellites; spp., sampled species (gra: L. granatensis; eur: L. europaeus; tim: L. timidus).

Species codes in mtDNA and $Y$ chromosome data indicate the origin of detected lineages.

Codes of sampling localities are the same as in Figure 1

aData from the study by Melo-Ferreira et al. (2007).

bData from this work ( 30 specimens) and from the study by Melo-Ferreira et al. (2005) (76 specimens).

'Data from the study by Melo-Ferreira et al. (2009). See Supplementary Tables S2 and S3 for a detailed description of the analysed mtDNA and X-chromosome data.

dSequences of 14 of these specimens were from the study by Melo-Ferreira et al. (2011).

e Sequences of six of these specimens were from the study by Melo-Ferreira et al. (2009).

\section{Genotype data analysis}

Standard measures of genetic diversity such as the total number of alleles per sample, mean number of alleles per locus, observed $\left(H_{0}\right)$ and non-biased expected $\left(H_{e}\right)$ heterozygosity were calculated using the programme Genetix (Belkhir et al., 1996-2004). Linkage disequilibrium between pairs of loci and Hardy-Weinberg equilibrium over all loci across all samples were estimated using Genepop (Raymond and Rousset, 1995). Differentiation between species and between pairs of populations was assessed by $F_{\mathrm{ST}}$ estimates using the same software.

In order to assess the ability of the microsatellite set to discriminate the three species, a non-parametric factorial correspondence analysis was performed using Genetix. In addition, the admixture model implemented in 
STRUCTURE (Pritchard et al., 2000) was applied both to the complete data set and to another composed only by $L$. granatensis and L. europaeus samples. This method allowed both determining the ability of the microsatellite markers to separate the species and pinpointing admixed individuals. Five replicate runs of STRUCTURE, with 500000 steps after a burn-in period of 100000 , were performed for each data set. No information about putative parental population was given a priori.

Evidence of admixture was in addition assessed using NewHybrids (Anderson and Thompson, 2002) in the data set composed only of L. granatensis and L.europaeus. NewHybrids is a model-based Bayesian software that assigns individuals to genotypic classes of parentals and several hybrid generations. Six classes were used here: pure L. granatensis, pure $L$. europaeus, F1, F2, backcross with $L$. granatensis and backcross with $L$. europaeus. Five replicate runs of 500000 sweeps after 100000 generations of burn-in were performed using a Jeffreys prior for both $\pi$ and $\Theta$.

Finally, microsatellite data collected from specimens sampled near the contact zone in Álava (Table 1) were analysed in a mixed genetic and spatial framework. This was performed using Geneland (Guillot et al., 2005), which was designed to detect population structure using geo-referenced individual multi-locus genetic data. Further, mean minimum annual temperatures (measured in ${ }^{\circ} \mathrm{C}$ ) and mean annual precipitation (measured in $\mathrm{mm}$ ) of the sampling locations of $L$. granatensis and $L$. europaeus in Álava (ALA1 and ALA2) were downloaded from the WorldClim website (www.worldclim.org; $1 \times 1 \mathrm{~km}$ resolution; Hijmans et al., 2005). Differences between the L. granatensis and $L$. europaeus sampling locations for these measures were tested using the Mann-Whitney $U$-test.

\section{mtDNA and microsatellite differentiation in the contact zone}

To estimate levels of differentiation of the L. timidus mtDNA type along and across the contact zone between $L$. granatensis and $L$. europaeus we used previously published sequences from the three pairs of populations (ALA1ALA2, NAV1-NAV2, ZAR-JAC; see Figure 1 and Table 1; Melo-Ferreira et al., 2007). Differentiation was estimated both for the mtDNA and microsatellite data using the hierarchical analysis of molecular variance approach implemented in Arlequin 3.5 (Excoffier and Lischer, 2010). Populations were partitioned according to species.

mtDNA typing, X-chromosome loci sequencing and Y-linked data In order to better characterise genetic exchanges in the contact zone, we studied the samples from the province of Álava (ALA1 and ALA2 in Figure 1) for additional markers: for mtDNA (PCR-RFLP typing), the X chromosome (sequences of four loci) and the Y chromosome (PCR-RFLP from a previous study; Melo-Ferreira et al., 2009). A previous PCR-RFLP typing of the mtDNA lineage of 71 individuals (Melo-Ferreira et al., 2005) was here extended to a total of 101 specimens using the same methodology (see primers in Supplementary Table S1, this assay allows recognising the three species-specific mtDNA lineages). Males were identified using an approach similar to that in the study by Wallner et al. (2001) and combining a Y-specific primer pair (with Sry primers adapted here, see Supplementary Table S1) with an autosomal specific one as internal control. Sry-negative samples for this duplex PCR were further assayed with the Sry primers alone, to detect potential false negatives that could have resulted from competition between primers during the initial duplex PCR.

Sequencing of loci located on the $\mathrm{X}$ chromosome was either an important extension of previous work (in the cases of Phka2 and Msn; Melo-Ferreira et al., 2009, 2011) or performed de novo (in the case of Smcx and Hprt1) (see Supplementary Tables S2 and S3). These genes were chosen based on their positions along the $\mathrm{X}$ chromosome (determined in the European rabbit and assuming synteny with hares, which is vastly observed for the autosomes) (Robinson et al., 2002): Phka2 and Hprt1 lie close to the telomeres, where recombination is expected to be high, and Smcx and Msn close to the centromere where recombination is expected to be low. A combination of newly and previously designed primers (Geraldes et al., 2006; Melo-Ferreira et al., 2009, 2011; see Supplementary Table S1) served to PCR-amplify these X fragments. PCR cycling profile consisted of an initial denaturation step at $94{ }^{\circ} \mathrm{C}$ for $15 \mathrm{~min}, 35$ cycles of $30 \mathrm{~s}$ at $94^{\circ} \mathrm{C}, 45 \mathrm{~s}$ at various annealing temperatures
(Supplementary Table S1) and $90-120 \mathrm{~s}$ at $72^{\circ} \mathrm{C}$, followed by a final extension at $60^{\circ} \mathrm{C}$ for $20 \mathrm{~min}$. Amplified fragments were sequenced in one or both directions (primers listed in Supplementary Table S1) following the ABI PRISM BigDye Terminator Cycle Sequencing 3.1 standard protocol and using an ABI PRISM 3130 sequencer (Applied Biosystems).

\section{$\mathrm{X}$-linked sequence data analysis}

Sequences of the four X-linked markers were edited, aligned, assembled and visually inspected using Bioedit 7.0.9.0 (Hall, 1999). Levels of genetic diversity were assessed by calculating several summary statistics using DnaSP 5.10 (Librado and Rozas, 2009), including the number of segregating sites (S), two estimators of nucleotide diversity, $\pi$ and $\theta$, and the nucleotide distance $\left(D_{x y}\right)$ to an outgroup (the European wild rabbit, Oryctolagus cuniculus). The same software was used to test for deviations from the neutral expectations under stable demography using Tajima's $D$ (Tajima, 1989) and Fu's $F_{S}(\mathrm{Fu}, 1997)$ statistics as well as the intra-locus population recombination parameter $\gamma$ (Hey and Wakeley, 1997).

Genetic differentiation between $L$. granatensis and $L$. europaeus was estimated using $F_{\mathrm{ST}}$, the average pairwise nucleotide divergence $\left(D_{x y}\right)$, and the number of fixed differences, also using DnaSP 5.10 (Librado and Rozas, 2009). Finally, median-joining networks were constructed using Network 4.600 (Bandelt et al., 1999) to represent genealogical relationships among haplotypes.

\section{RESULTS}

\section{Species distinction and inferences of hybridisation using microsatellites}

We included in our analysis of microsatellite differentiation along the contact zone between $L$. europaeus and $L$. granatensis some reference populations far away from this zone (Figure 1 for the distribution of samples), but also some L. timidus samples because of the known mtDNA timidus contribution in this region in both species. Considering all 342 genotyped individuals from the three species, 73 alleles were found at the six microsatellite loci, with 5-20 alleles per locus (Supplementary Table S4; see distribution of allelic frequencies per locus in Supplementary Figure S1). The mean number of alleles per locus, as well as $H_{\mathrm{e}}$ and $H_{\mathrm{o}}$ were in general lower in $L$. granatensis than in L. europaeus or L. timidus, which displayed similar values of diversity (see diversity per population in Supplementary Tables S5 and S6). Across all populations, only three population-locus tests suggested significant deviations from Hardy-Weinberg proportions after Bonferroni correction, and we found no evidence of linkage disequilibrium among loci.

The $F_{S T}$ estimates showed much higher levels of inter- than intraspecific differentiation (Supplementary Table S7). Accordingly, the three species appeared as separate clusters in both 2D-AFC (Supplementary Figure S2) and STRUCTURE (Supplementary Figure S3) results. In the STRUCTURE analysis of the three species $(K=3), 12$ individuals fell below the defined threshold of $80 \%$ of assignment to a given species, and could thus be of mixed ancestry (Supplementary Figure S3): one L. timidus specimen from the Alps (admixed with $L$. europaeus), two $L$. europaeus specimens from Austria (admixed with L. timidus), three L. europaeus from Iberia (two admixed with $L$. timidus and one with $L$. granatensis) and six L. granatensis (five admixed with L. europaeus and one almost evenly assigned to the three species).

Focusing only on admixture between $L$. granatensis and L. europaeus and after removing the specimens with suggestions of admixture with $L$. timidus, we ran STRUCTURE again but with $K=2$, which returned six individuals with evidence of admixture between L. granatensis and L. europaeus (Figure 2). All these specimens were collected in the Spanish province of Álava, five in the area of distribution of L. granatensis and one in that of L. europaeus. These 
results were almost totally supported by those of NewHybrids, the only exception being one individual from the L. granatensis sample of Álava, which was assigned with high posterior probability to parental L. granatensis (Figure 2). The remaining five individuals had a posterior probability of assignment to the non-F1 hybrid classes of $\sim 0.50$ or more. Two additional L. europaeus specimens from Álava and Jaca had similarly high posterior probabilities of assignment to

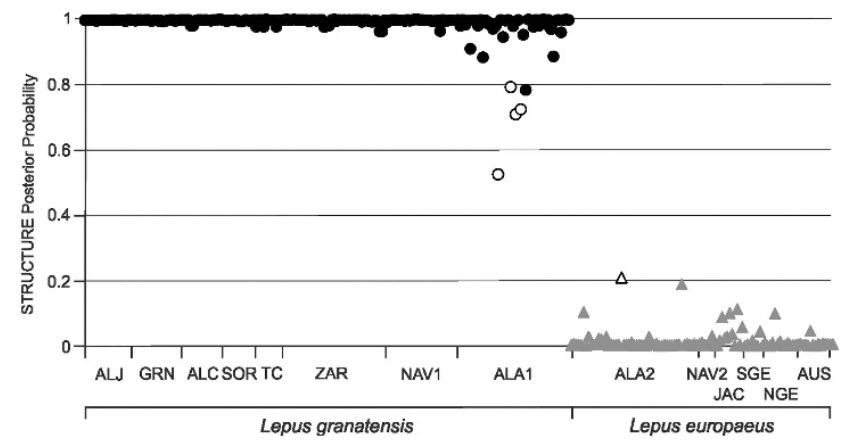

Figure 2 Posterior probabilities of assignment to $L$. granatensis of L. granatensis (circles) and L. europaeus (triangles) specimens sampled in the populations indicated along the $x$ axis (check codes in Figure 1 and Table 1) inferred using STRUCTURE from microsatellite variation. Open symbols indicate specimens that were identified as admixed both in the STRUCTURE and NewHybrids analyses.

Table 2 Analysis of molecular variance of mtDNA and microsatellites on three pairs of populations sampled along the contact zone between $L$. granatensis and $L$. europaeus and partitioned according to species

\begin{tabular}{lrrrrrrr}
\hline & \multicolumn{3}{c}{ Fixation indices } & & \multicolumn{3}{c}{ Percentage of variance } \\
\cline { 2 - 4 } & $\Phi_{S C}$ & $\Phi_{S T}$ & $\Phi_{C T}$ & & $A G$ & APWG & WP \\
\hline mtDNA & 0.273 & 0.294 & -0.030 & & -3.0 & 30.3 & 72.7 \\
Microsatellites & 0.052 & 0.363 & 0.328 & & 32.8 & 3.5 & 63.7
\end{tabular}

Abbreviations: AG, among groups; APWG, among populations within groups; WP, within populations.

See Figure 1 for the composition of each group.
non-F1 hybrid classes but had not been identified as admixed by STRUCTURE (data not shown).

\section{mtDNA and microsatellite differentiation along and across the contact zone}

Using only the three pairs of populations across the contact zone between L. granatensis and L. europaeus (pairs ALA1-ALA2, NAV1NAV2 and JAC-ZAR; Figure 1) we compared the results of an analysis of molecular variance considering the species and population levels. For mtDNA, we only considered variants of $L$. timidus origin in both species (which were the majority in the sequence data of MeloFerreira et al., 2007 used here) for these analyses to make sense. Table 2 shows that for mtDNA differentiation among species is very low and non-significant, as opposed to high and significant differentiation among populations of the same species, that is, of the same order as overall between population differentiation (see also the distribution of major lineages of timidus origin in Supplementary Figure S4). The reverse pattern is seen for microsatellites, with low differentiation among populations of the same species, and comparatively high differentiation between species (although the former is significantly different from 0 but not the latter after the permutation tests). Therefore, these combined results conform to the prediction we made in the case of repeated hybridisation of $L$. europaeus during its likely East-West progression in a territory occupied by L. granatensis.

\section{Genetic and geographic analysis of the contact zone}

As admixture was only detected in the province of Álava using microsatellites, we further focused on this area to study in more detail contemporaneous genetic exchanges between these species. The results of an analysis of the microsatellite data with Geneland, which takes into account the geographic location of samples, point to a sharp genetic discontinuity coinciding with a ridge of the Sierra de Cantabria, which partitions the samples according to their morphological assignation (Figure 3). The analyses of annual temperature and precipitation in the two regions thus partitioned suggest that the north is significantly wetter and colder, and the south hotter and drier (Mann-Whitney $U$-test, $P=0.046$ for mean of minimum annual temperatures, $P<0.001$ for mean annual precipitation; see detailed information in Supplementary Table S2).

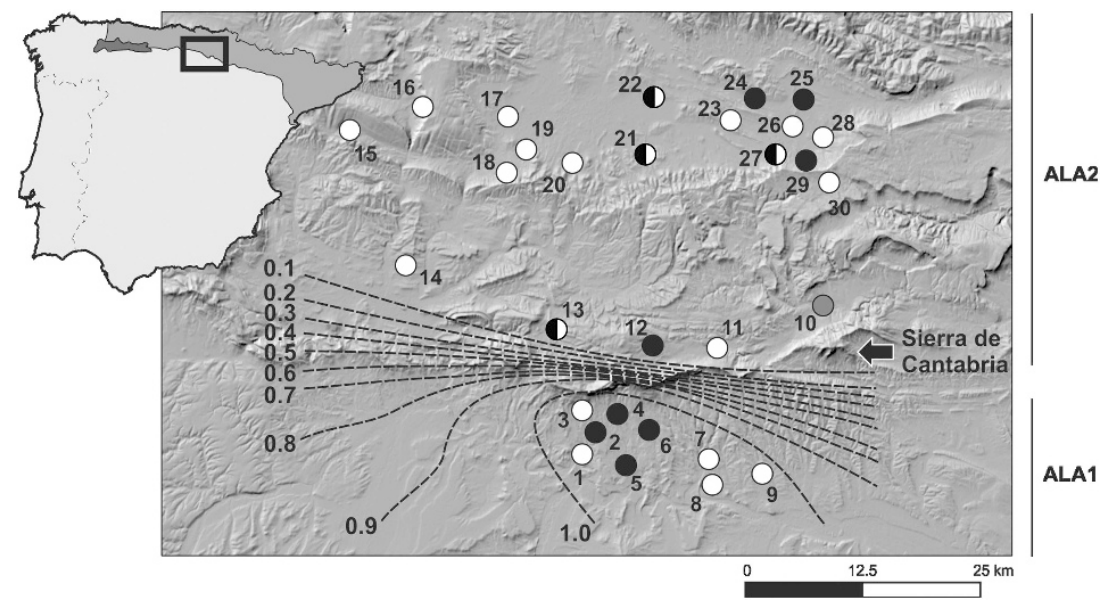

Figure 3 Hillshaded map of the region of Álava, Spain (location indicated by box on the map of the Iberian Peninsula). Circles indicate sampling locations and their colours the mtDNA haplotype detected in each locality: white - L. timidus, black - L. granatensis and grey - L. europaeus (coordinates of sampling localities and sample sizes in Supplementary Table S2). Dashed lines indicate the posterior probabilities of assignment to $L$. granatensis inferred using Geneland. 
The distribution of mtDNA types (assigned to each of the three species by PCR-RFLP) is also shown on Figure 3. In the territory of L. granatensis as defined by the Geneland analysis, both the granatensis and timidus mtDNA were found, with a predominance of the former (34 out of 48), in keeping with the earlier descriptions by Melo-Ferreira et al. (2005) based on PCR-RFLP data but a more limited sample (Table 1; Figure 3). In the L. europaeus range, the timidus lineage prevailed (34 out of 53) and the europaeus lineage was rare (only 2), in keeping with the results of the study by Melo-Ferreira et al. (2005). However, contrary to these previous results, we found relatively high frequencies of the granatensis lineage (17 out of 53, Table 1; Figure 3). The distribution of these mtDNA lineages in Álava does not show any pattern coinciding with the microsatellite discontinuity across the mountain ridge (Figure 3), and the high frequency of granatensis in europaeus territory contrasts with the high microsatellite differentiation and the rarity of admixed genotypes detected. This reinforces the observation of less mtDNA than microsatellite differentiation across the contact zone that was pointed by the analyses of molecular variance (see above).

Sequences of four X-linked loci (fragments of genes Phka2, Smcx, Msn and Hprt1) were analysed in up to 36 individuals of L. granatensis and 32 individuals of L. europaeus from Álava, and also for up to $10 \mathrm{~L}$. timidus (Table 1; Supplementary Table S3). Most analysed specimens were males, which allowed the direct recovery of haplotypes. The few genotyped females (Supplementary Tables S2 and S3) were found to either be homozygous for all SNPs or to present a single SNP at any given locus, which also allowed recovering the segregating haplotypes. The data set contained a total of 286 sequences (77 for Phka2, 75 for Smcx, 82 for Msn and 52 for Hprt1; 2 sequences per female), of which 22 were from previous studies (Melo-Ferreira et al., 2009, 2011; see Supplementary Table S2, S3 and S8; GenBank Accession Numbers of the new sequences: KF564322KF564553). Contrary to what we observed for microsatellites, diversity was higher in $L$. granatensis than in $L$. europaeus (Supplementary Table S8). In general, genetic diversity was higher at the two distal loci (Phka2, Hprt1) than at the two proximal (Msn and $S m c x$ ). The ratio $\theta / D x y$ (Supplementary Table S8) was generally higher for the telomeric than centromeric genes, which suggests that differences in diversity do not reflect differences in mutation rates, but could result from, for example, different recombination rates, low recombining regions being more affected by linkage to selected loci.
Equilibrium and neutrality tests could not be performed for all loci in both species due to the absence of polymorphism at some markers, but were generally found not to be significant (Supplementary Table S8). Levels of differentiation and divergence between $L$. granatensis and L. europaeus also differed between the two X-chromosome regions, $F_{\mathrm{ST}}$ being higher and $D_{x y}$ lower proximally (Supplementary Table S8). Phylogenetic analyses using several autosomal loci had suggested that L. granatensis and L. timidus were more closely related as compared with $L$. europaeus (Melo-Ferreira et al., 2012). Our results are compatible with this in all X loci except Phka2. However, in all cases europaeus haplotypes appear very different from those of the two other species, and no shared haplotypes were found between L. granatensis and L. europaeus at any locus (Figure 4). No statistical evidence of intra-locus recombination was found in our data sets (Supplementary Table S8). However, a more detailed analysis of the Phka2 locus (Melo-Ferreira et al., 2011 and unpublished results) has shown evidence that some of the haplotypes found in L. granatensis are recombinant between granatensis and timidus haplotypes (haplotypes G1-G3 in Figure 4a). However, we find no evidence here that these chimeric haplotypes, which are frequent everywhere in the L. granatensis range, including close to this contact zone (Melo-Ferreira et al., 2011 and this study), exist in L. europaeus. Finally, a previous study using samples from the province of Álava had not detected any exchange of Y chromosome either between the three species (Melo-Ferreira et al., 2009; Table 1).

\section{DISCUSSION}

The North of the Iberian Peninsula has been an arena for reticulate evolution among different species of hares at least since the last glacial period and presumably during more ancient periods as well (MeloFerreira et al., 2005, 2009, 2012). Understanding the origin of the apportionment of genetic diversity among the extant hare species implies understanding the influence of past range shifts in relation to climate changes accompanied by species interactions and hybridisation, including with a locally extinct species. It also implies understanding the influence of present exchanges across extant secondary hybrid zones. The fact that the past interaction and hybridisation with the now extinct $L$. timidus has affected the three species now thriving in Iberia complicates the analysis of ongoing gene flow using markers for which diagnosticity is thus potentially compromised (Alves et al., 2006). However, previous species-wide studies with several autosomal

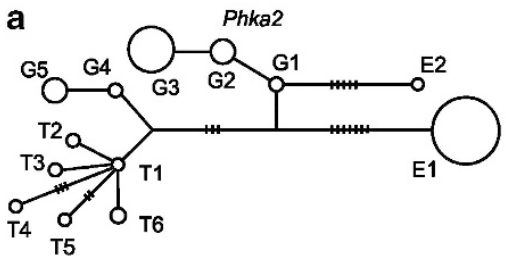

b

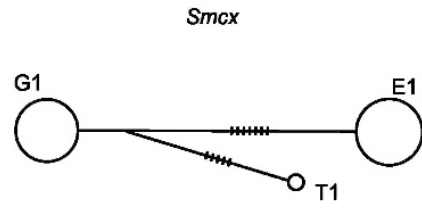

C

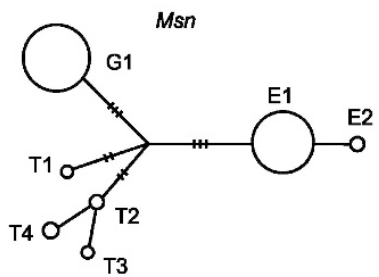

d

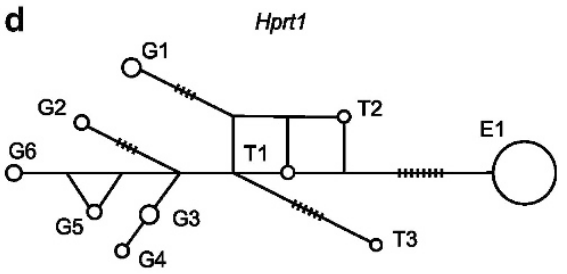

Figure 4 Median-joining networks of the sequenced X-linked loci: (a) Phka2, (b) Smcx, (c) Msn and (d) Hprt1. The first letter of each haplotype indicates the species where it was detected: $G$ - $L$. granatensis, E- L. europaeus and T-L. timidus. Localities and sample sizes are indicated in Table 1 . Dashes on the branches indicate the number of mutations if higher than one. Haplotypes' areas are proportional to their frequency. 
markers have shown that reticulation left large scale traces only for mtDNA, nuclear introgression being generally only sporadic (MeloFerreira et al., 2009, 2012). The only notable exception is an $\mathrm{X}$-chromosome fragment that was shown to have largely spread from L. timidus into the full range of L. granatensis (Melo-Ferreira et al., 2011). Theoretical predictions have provided a potential explanation for this contrast between genomic regions, suggesting that it results from the combination of demographic processes during range replacement with differences of sex-linked transmission between genomic regions and sex-linked differences in migration behaviour. However, the precise dynamics of the corresponding process, including the relative influences of hybridisation frequency, drift intensity and demographic expansion rate, is well modelled but poorly documented in real life, even if it can explain numerous cases of mtDNA introgression (Petit and Excoffier, 2009). Understanding the conditions under which the phenomenon occurred may be of interest to reconstruct past history and evolution. If introgression resulted from rare hybridisation accidents associated with extreme stochasticity, followed by allele surfing on high waves, such observations would remain somewhat anecdotal, unless other sources of information indicated a secondary impact on genetic evolution and genome coadaptation. However, in the case of hares, the phenomenon has occurred in the three species that inhabit Iberia, and even apparently repeatedly in L. castroviejoi (Melo-Ferreira et al., 2012). This suggests that hybridisation has been systematic rather than anecdotal during climate-driven range shifts, and that it must thus have also occurred repeatedly during the expansion of any given species. If this was true, then the present distribution of introgressed alleles would have kept to a certain extent the memory of past species distribution and variation before range shifts associated with major environmental changes. Here we took advantage of the existence of a contact zone between two species that evolved independently and colonised the area through independent routes to test the hypothesis that mtDNA variation witnesses past population structure in the face of invasion by two species.

\section{Limited genetic admixture in the contact zone between L. granatensis and L. europaeus}

The microsatellites used in this work allowed a clear separation of the three hare species. Even including samples from the contact zone, the specimens were attributed with high probabilities to the species they had been classified into based on evident morphological characters (the only exception among the 342 studied specimens was one sampled in the Alps, possibly erroneously identified as belonging to L. timidus; Supplementary Figure S3). Signs of autosomal introgression from L. timidus had been previously estimated to be rare in the Iberian species based on diagnostic SNPs (Melo-Ferreira et al., 2009). In keeping, we assessed little putative contribution of L. timidus in the Iberian Peninsula with microsatellites (Supplementary Figure S3). However, given the mode and rate of mutation of microsatellites, and the general absence of fully diagnostic loci, our set of six autosomal loci was expected to be particularly suitable to assess recent gene flow between neighbouring populations rather than ancient gene flow. Therefore, it is at this point difficult to assess whether the inference of L. timidus genetic contribution results from direct admixture with L. timidus (for example on the way to colonise Iberia) or from putative background noise due to genetic admixture with an unsampled but well-differentiated population (for example, $L$. castroviejoi). The admixture found in the two Austrian specimens may eventually result from recent hybridisation between $L$. timidus and
L. europaeus closer to the Alps, as previously suggested (Suchentrunk et al., 2005; Melo-Ferreira et al., 2009).

Evidence of admixture between L. granatensis and L. europaeus was found only in Álava in northern Spain (ALA1 and ALA2 in Figure 1), the localities closest to the contact zone between the two species. The four L. granatensis specimens and one L. europaeus with evidence of admixture were inferred to be backcrosses, suggesting that hybrids between these species are fertile, at least to a certain degree. However, no exchange could be detected for the sex chromosome markers, which may be an indication that they are implicated in hybrid unfitness, as is often the case (Presgraves, 2008). Even an X marker (Phka2), which had previously shown to have extensively introgressed from L. timidus into L. granatensis (Melo-Ferreira et al., 2011), did not show any evidence of gene flow from either L. timidus or L. granatensis into L. europaeus.

Overall, the contact between $L$. granatensis and L. europaeus appears to be a zone of little exchange between the species, with evidence of sporadic gene flow, but no real hybrid population. The fine scale study we performed in Álava suggests that the two species have distinct ecological preferences, which could account for their non-overlapping distributions and contribute to impede gene flow. It may also explain the success of the past invasion of L. europaeus, into an area where it would have been better adapted than L. granatensis. Although the analysis of habitat differentiation was here performed at a small geographical scale and using a limited number of variables, a strong habitat dependence of the two species has been inferred by ecological modelling (Acevedo et al., 2012a,b), which suggests that habitat is likely a major determinant of species ranges, contributing to the maintenance of species segregation, as is often observed in secondary contact zones (Sexton et al., 2009). These ecological modelling studies also suggest that the ongoing climate change will likely induce an expansion of $L$. granatensis towards the north and a retraction of L. europaeus, which may have implications for the management of these game species (Acevedo et al., 2012a).

mtDNA differentiation is independent of species barriers The most striking result of our study is the lack of mtDNA differentiation across the contact zone between L. europaeus and L. granatensis (in comparison to substantial differentiation among populations of the same species) and its contrast with the sharp differentiation for nuclear genes (Table 2). Note that this resemblance across the contact zone prevails whether mtDNA is of L. granatensis origin (high prevalence in both species in Álava; see Table 1) or of L. timidus origin (results of the analyses of molecular variance between species; Table 2). Such resemblance is hardly explained by gene flow across the contact zone, which we have shown to be extremely limited, but must rather reflect mtDNA diversity that existed before the two species entered into contact, that is, before L. europaeus entered Iberia. The fact that granatensis mtDNA is found at high frequencies in L. europaeus in Álava is a strong indication that L. granatensis rather than L. timidus was present in more northern Iberian latitudes before it was replaced by L. europaeus. Previous analyses of nuclear species-diagnostic SNPs had failed to detect any trace of L. timidus genome in Iberian L. europaeus (Melo-Ferreira et al., 2009), but the present study has suggested possible such cases in two specimens. It could be that $L$. europaeus hybridised with L. timidus before it entered Iberia (several such cases have been documented in present populations; Suchentrunk et al., 2005; Thulin et al., 2006). Alternatively, the populations it replaced in Iberia could have been hybrids between L. timidus and L. granatensis, which is plausible if the replacement of L. timidus by L. granatensis was still 
incomplete when $L$. europaeus arrived. Many more markers would be needed to eventually solve this question, but our present conclusions hold whatever was the exact composition of the hare populations that L. europaeus replaced.

\section{CONCLUSION}

Taking advantage of the favourable geographical setting of the interaction between L. europaeus and L. granatensis, we have demonstrated that repeated hybridisation along the invasion front was a major determinant of the massive mtDNA introgression into L. europaeus. The same is likely to be true for the two other species of Iberia, which provides a plausible explanation for the systematic occurrence of the phenomenon. The mtDNA variability presently found in Northern Iberia thus reflects to a certain extent the diversity that was present in L. timidus before the major species range shifts that led the three other species to occupy the region. The home-loving boreal mitochondrial genome therefore survived several alien invasions in Northern Iberia and became a stowaway successively in two different species ( $L$. granatensis followed by $L$. europaeus), and apparently also twice in the same species (L. castroviejoi). Note though that the clandestineness of this passenger would deserve critical examination, because its high prevalence could have influenced the evolution and adaptation of its carriers. As hybrid zones are often established after species range shifts, mtDNA may often mark ancient species distribution rather than current gene flow across a hybrid zone stabilised after a major environmental change.

\section{DATA ARCHIVING}

Sequence data are deposited in GenBank: accession numbers KF564322-KF564553. Genotype data and final sequence alignments are deposited in Dryad: doi:10.5061/dryad.qj864.

\section{CONFLICT OF INTEREST}

The authors declare no conflict of interest.

\section{ACKNOWLEDGEMENTS}

This work was partially supported by FEDER (Fundo Europeu de Desenvolvimento Regional) funds through the Programa Operacional Factores de Competitividade (COMPETE program; FCOMP-01-0124-FEDER-014266) and Portuguese national funds through the FCT (Fundação para a Ciência e a Tecnologia; PTDC/BIA-EVF/111931/2009 research project), by Programa Operacional Potencial Humano (POPH) - Quadro de Referência Estratégico Nacional (QREN) funds from the European Social Fund and Portuguese Ministério da Educação e Ciência (FCT, SFRH/BPD/43264/2008 post-doctoral grant to JM-F), and by project 'Genomics and Evolutionary Biology' co-financed by North Portugal Regional Operational Programme 2007/2013 (ON.2 - O Novo Norte), under the National Strategic Reference Framework (NSRF), through the European Regional Development Fund (ERDF). We thank Ibon Teletxea (ACCA-Asociación de Cotos de Caza de Álava) for providing most of the Álava samples, Christian Gortázar, Rafael Villafuerte, Diego Villanúa and Miguel Delibes-Mateos for their help in sampling the other Spanish populations, and Ettore Randi for providing the Italian L. timidus samples. We also thank Pedro Tarroso for his help with the hillshaded map of Álava and the climatic variables and Fernando Sequeira for valuable comments on the microsatellite analyses. Microsatellite genotyping and DNA sequencing was performed on the platform of LabEx CeMEB (Centre Méditerranéen de l'Environnement et de la Biodiversité, Montpellier) and in Centro de Testagem Molecular (CTM) of CIBIO.

Author contributions: JM-F, PB and PCA conceived the work. JM-F, HF and LF performed the laboratory work and data analyses. JM-F and PB drafted the manuscript. All authors interpreted the results, revised and approved the final version of the manuscript.
Acevedo P, Jiménez-Valverde A, Melo-Ferreira J, Real R, Alves PC (2012a). Parapatric species and the implications for climate change studies: a case study on hares in Europe. Global Change Biol 18: 1509-1519.

Acevedo P, Melo-Ferreira J, Real R, Alves PC (2012b). Past, present and future distributions of an Iberian endemic, Lepus granatensis: ecological and evolutionary clues from species distribution models. PLoS One 7: e51529.

Altuna J (1970). Hallazgo de una liebre artica (Lepus timidus) en el yacimiento prehistorico de Urtiga (Guipuzcoa). Munibe 22: 165-168.

Alves PC, Ferrand N, Suchentrunk F, Harris DJ (2003). Ancient introgression of Lepus timidus mtDNA into $L$. granatensis and $L$. europaeus in the Iberian Peninsula. Mol Phylogenet Evol 27: 70-80.

Alves PC, Harris DJ, Melo-Ferreira J, Branco M, Ferrand N, Suchentrunk F et al. (2006). Hares on thin ice: Introgression of mitochondrial DNA in hares and its implications for recent phylogenetic analyses. Mol Phylogenet Evol 40: 640-641.

Alves PC, Melo-Ferreira J, Freitas H, Boursot P (2008). The ubiquitous mountain hare mitochondria: multiple introgressive hybridization in hares, genus Lepus. Philos $T R$ Soc B 363: 2831-2839.

Anderson EC, Thompson EA (2002). A model-based method for identifying species hybrids using multilocus genetic data. Genetics 160: 1217-1229.

Bandelt HJ, Forster P, Rohl A (1999). Median-joining networks for inferring intraspecific phylogenies. Mol Biol Evol 16: 37-48.

Belkhir K, Borsa P, Chikhi L, Raufaste N, Bonhomme F (1996-2004). GENETIX 4.05, logiciel sous Windows TM pour la génétique des populations. Laboratoire Génome, Populations, Interactions, CNRS UMR 5171, Université de Montpellier II: Montpellier (France).

Chantry-Darmon U, Urien C, Hayes H, Bertaud M, Chadi-Taourit S, Chardon P et al. (2005). Construction of a cytogenetically anchored microsatellite map in rabbit. Mamm Genome 16: 442-459.

Currat M, Ruedi M, Petit RJ, Excoffier L (2008). The hidden side of invasions: massive introgression by local genes. Evolution 62: 1908-1920.

Estonba A, Solis A, Iriondo M, Sanz-Martin MJ, Perez-Suarez G, Markov G et al. (2006) The genetic distinctiveness of the three Iberian hare species: Lepus europaeus, L. granatensis, and L. castroviejoi. Mamm Biol 71: 52-59.

Excoffier L, Lischer HEL (2010). Arlequin suite ver 3.5: A new series of programs to perform population genetics analyses under Linux and Windows. Mol Ecol Resour 10: 564-567.

Excoffier L, Ray N (2008). Surfing during population expansions promotes genetic revolutions and structuration. Trends Ecol Evol 23: 347-351.

Fickel J, Lieckfeldt D, Pitra C (1999). Analysis of genetic diversity and structure in neighboring populations of the European brown hare (Lepus europaeus, Pallas 1778). Zeitschrift Fur Jagdwissenschaft 45: 230-237.

Fu YX (1997). Statistical tests of neutrality of mutations against population growth, hitchhiking and background selection. Genetics 147: 915-925.

Geraldes A, Ferrand N, Nachman MW (2006). Contrasting patterns of introgression at X-linked loci across the hybrid zone between subspecies of the European Rabbit (Oryctolagus cuniculus). Genetics 173: 919-933.

Guillot G, Estoup A, Mortier F, Cosson JF (2005). A spatial statistical model for landscape genetics. Genetics 170: 1261-1280.

Hall TA (1999). BioEdit: a user-friendly biological sequence alignment editor and analysis program for Windows 95/98/NT. Nucl Acids Symp Ser 41: 95-98.

Hewitt GM (2000). The genetic legacy of the Quaternary ice ages. Nature 405: 907-913.

Hey J, Wakeley J (1997). A coalescent estimator of the population recombination rate. Genetics 145: 833-846.

Hijmans RJ, Cameron SE, Parra JL, G JP, Jarvis A (2005). Very high resolution interpolated climate surfaces for global land areas. Int J Climatol 25: 1965-1978.

Kryger U, Robinson TJ, Bloomer P (2002). Isolation and characterization of six polymorphic microsatellite loci in South African hares (Lepus saxatilis F. Cuvier, 1823 and Lepus capensis Linnaeus, 1758). Mol Ecol Notes 2: 422-424.

Librado P, Rozas J (2009). DnaSP v5: a software for comprehensive analysis of DNA polymorphism data. Bioinformatics 25: 1451-1452.

Melo-Ferreira J, Alves PC, Freitas H, Ferrand N, Boursot P (2009). The genomic legacy from the extinct Lepus timidus to the three hare species of Iberia: contrast between mtDNA, sex chromosomes and autosomes. Mol Ecol 18: 2643-2658.

Melo-Ferreira J, Alves PC, Rocha J, Ferrand N, Boursot P (2011). Interspecific X-chromosome and mitochondrial DNA introgression in the Iberian hare: selection or allele surfing? Evolution 65: 1956-1968.

Melo-Ferreira J, Boursot P, Carneiro M, Esteves PJ, Farelo L, Alves PC (2012). Recurrent introgression of mitochondrial DNA among hares (Lepus spp.) revealed by species-tree inference and coalescent simulations. Syst Biol 61: 367-381.

Melo-Ferreira J, Boursot P, Randi E, Kryukov A, Suchentrunk F, Ferrand N et al. (2007). The rise and fall of the mountain hare (Lepus timidus) during Pleistocene glaciations: expansion and retreat with hybridization in the Iberian Peninsula. Mol Ecol 16 605-618.

Melo-Ferreira J, Boursot P, Suchentrunk F, Ferrand N, Alves PC (2005). Invasion from the cold past: extensive introgression of mountain hare (Lepus timidus) mitochondrial DNA into three other hare species in northern Iberia. Mol Ecol 14: 2459-2464.

Mougel F, Mounnolou JC, Monnerot M (1997). Nine polymorphic microsatellite loci in the rabbit, Oryctolagus cuniculus. Anim Genet 28: 58-71.

Petit RJ, Excoffier L (2009). Gene flow and species delimitation. Trends Ecol Evol 24 386-393.

Presgraves DC (2008). Sex chromosomes and speciation in Drosophila. Trends Genet 24 336-343. 
Pritchard JK, Stephens M, Donnelly P (2000). Inference of population structure using multilocus genotype data. Genetics 155: 945-959.

Raymond M, Rousset F (1995). GENEPOP (version 1.2): a population genetics software for exact tests and ecumenicism. J Hered 86: 248-249.

Robinson TJ, Yang F, Harrison WR (2002). Chromosome painting refines the history of genome evolution in hares and rabbits (order Lagomorpha). Cytogenet Genome Res 96 : 223-227.

Sexton JP, Mclntyre PJ, Angert AL, Rice KJ (2009). Evolution and ecology of species range limits. Annu Rev Ecol Evol Syst 40: 415-436.

Stamatis C, Suchentrunk F, Moutou KA, Giacometti M, Haerer G, Djan M et al. (2009). Phylogeography of the brown hare (Lepus europaeus) in Europe: a legacy of southeastern Mediterranean refugia? J Biogeogr 36: 515-528.
Suchentrunk F, Mamuris Z, Stamatis C, Ben Slimen H, Hackländer K, Haerer G et al. (2005). Introgressive hybridization in wild living mountain hares (L. timidus varronis) and brown hares (L. europaeus) and morphological consequences. Mamm Biol 70:suppl 39-40.

Tajima F (1989). Statistical method for testing the neutral mutation hypothesis by DNA polymorphism. Genetics 123: 585-595.

Thulin CG, Fang M, Averianov AO (2006). Introgression from Lepus europaeus to L. timidus in Russia revealed by mitochondrial single nucleotide polymorphisms and nuclear microsatellites. Hereditas 143: 68-76.

Wallner B, Huber S, Achmann R (2001). Non-invasive PCR sexing of rabbits (Oryctolagus cuniculus) and hares (Lepus europaeus). Mamm Biol 66: 190-192.

Supplementary Information accompanies this paper on Heredity website (http://www.nature.com/hdy) 